\title{
Bioactivities of Extracts from Different Marine Organisms around the World (2000 to Present)
}

\author{
Angelo Mark P Walag* \\ Department of Science Education, University of Science and Technology of Southern Philippines, Philippines
}

Received: December 12, 2017; Published: December 15, 2017

*Corresponding author: Angelo Mark P Walag, Department of Science Education, University of Science and Technology of Southern Philippines, Cagayan de Oro City, 9000, Philippines; Email: walag.angelo@gmail.com

\section{Introduction}

Marine ecosystem covers $70 \%$ or more of the earth's surface. These ecosystems are habitat to a great diversity of marine organisms that produce highly structural diverse metabolites as defense mechanisms [1,2]. Of these marine organisms, invertebrates produce bioactive natural products that may be useful for developing and producing novel drugs [3,4]. Marine invertebrates include several species which cut across different taxa including Porifera, Annelids, Coelenterates (Cnidaria and Ctenophora), Mollusks, Echinoderms and etc. [3,5]. Several studies have already been conducted determining natural products from marine invertebrates and their biological activities and also the biosynthetic studies which lead to revision and modification of their structures [5]. In a study conducted to determine the bioactivity of sterols isolated from marine organisms, it was found out that sterols play as anti-inflammatory, antimicrobial, anti-HIV, and anticancer activities [6].

Sponges are the most studied marine invertebrate in terms of secondary metabolites. More than 5300 different chemically potent and bioactive substances have been discovered present in sponges and many of these substances have pharmaceutical activities against human diseases like malaria, AIDS, and cancer. These substances are classified as alkaloids, lipids, steroids, and terpenoids and some of these compounds exhibit cytotoxic activities like the polyacetylenic lipid derivatives, glycerol ethers, and linear alcohols. It was also found out that secondary metabolites from sponges are cytotoxic to human gastric tumor cells, KB-16 human cell line, ovarian sarcoma cell line, pancreatic cancer cell line, colorectal adenocarcinoma cell line $[4,7]$. Several secondary metabolites were also identified to have anti-inflammatory action in human neutrophils and possess inhibitory activities against $\alpha$-Glucosidase which is important in controlling glucose concentration [7]. Sponges were also found out to contain natural products that have anti-inflammatory, antioxidant, and immunomodulatory activities [8].

Other marine invertebrates also were studied and found to have antimicrobial, antioxidant, anti-cancer, anti-inflammation, cytotoxic activities. Natural products found from the extract of soft corals in
Vietnam were found to have significant inhibitory effects against $T$. brucei. The growth inhibition and cytotoxicity of pentamidine were evaluated in terms of $\mathrm{EC}_{50}$ value and against human cell lines [2]. Several secondary metabolites were also isolated and elucidated from marine crinoid invertebrate, Colobometra perspinosa, which demonstrated non-selective anti-cancer activity [9]. Dolabellanin, a 33 amino acid residue peptide from a mollusk sea hare from Japan also exhibits a broad spectrum of antimicrobial activity [5]. Secondary metabolites isolated from the digestive glands and mantle of nudibranchs were found to have mild toxicity against brine shrimp and very potent antimicrobial activity [5]. The extracts from a bivalve $P$. viridis showed antibacterial activity as reported in the assay where the extract had maximum zone of inhibition against $V$. cholerae [10]. It was also shown in the same study that the crude protein extract of $P$. viridis had a potential antioxidant activity.

New marine natural products were also identified and isolated from marine invertebrates under the phylum of Echinodermata as reported by the review of [3]. It was found out that for the last two decades, majority of the new marine natural products from this phylum came from sub-phylum Asterozoa (54.9\%) and was followed by sub-phylum Echinozoa (33.7\%). The classes Asteroidea and Holothuroidea of Phylum Echinodermata accounted for $91.7 \%$ of new marine natural products having 529 and 213 new marine natural products respectively [3]. It was also showed that since 1990, majority of the research on new marine natural products isolated has been focused on less than $1 \%$ of the recognized marine invertebrate biodiversity and that $7.4 \%$ came from the species under phylum Porifera while only $2.1 \%$ were yielded from phylum Echinodermata. Although only few were identified and isolated, echinoderm is considered as an exceptional source of polar steroids with vast structural diversity which shows a wide range of bioactivities [11].

Since 1990, 7.2 new natural products are discovered per species from the 1,849 valid species under Class Asteroidea and 74\% the species of this class are with new natural products [3]. Several studies are also reports the isolation of novel marine natural products this class with several bioactivities. Secondary metabolites 
from sea stars show a rich source of activity against microbes. These sea stars are Luidia maculate, Stellaster equestris, Astropecten indicus, Protoreaster lincki, Pentaceraster regulus crude, fractioned, ethanolic, n-butanol and methanolic extracts demonstrate antibacterial and antifungal activity against human pathogens [11] Crude extracts of the species Astropecten polyacanthus also possess inhibitory activities against inflammatory components [12]. Other sea stars like Tremaster novaecaledoniae, Asterias amurensis, Styracaster caroli, and Echinaster brasiliensis contain sterol compounds which exhibits inactivation activity against HIV 6.

Other sea stars also play cytotoxicity against cancer cells. Novel marine natural products were also elucidated from the species Leptasterias ochotensis demonstrated cytotoxic activities against cancer cell lines RPMI-7951 and T-47D [13]. Saponins isolated from the sea star, Culcita novaeguineae, showed cytotoxic activity against human carcinoma cell lines by the apoptosis of the cells $[14,15]$. The sea star species Asterina pectinifera exhibits an anticancer activity by preventing the initiation of enzymes involved in carcinogenesis in human colon cancer and breast cancer cell lines $[12,16]$. Cytotoxic activity against human cervical cancer cell line and human mouse epidermal cell line was also reported from the metabolites of asterosaponins from the species Archaster typicus [17]. Cytoxicity against a small panel of human solid tumor cell lines of Certonardoa semiregularis were evaluated and it was found out that several saponin compounds were active against five different cell lines $[6,18]$. It was also found out that two saponins were active against 20 clinically isolated strains. In another study, carotenoids of Marthasterias glacialis were evaluated in terms of cytotoxicity against rat basophilic leukemia cancer cell line and it was found out that toxicity was low as desired as an anti-cancer lead substance [19].

Antioxidant activities of extracts and isolated marine natural products from sea stars were also recorded and established. In a study [20], extracts of the sea star L. maculata showed a potential antioxidant activity in all four assays. The study also further established the presence of steroidal glycosides and glucocerebrosides which might be the responsible agents for the antioxidant activity. In another study, antioxidant activities and neuroprotective effect were reported from the polysaccharides extracted from the starfish Asterias rollestoni [21]. It was also found out that the mannoglucan sulfate had the highest antioxidant activity among all polysaccharides tested.These handful studies on bioactivities of extracts from different marine organisms were mostly conducted in temperate and Polar Regions, thus signifying the need to further and advance interest on marine organisms from biodiversity-rich tropical regions. Conservation efforts must be given priority especially with these marine organisms due to various threats of extinction due to climate change, and various destructive anthropogenic activities and pollution [22-24].

\section{References}

1. Grosso C, Valentão P, Ferreres F, Andrade PB (2015) Alternative and efficient extraction methods for marine-derived compounds. Mar Drugs 13(5): 3182-3230.
2. Thao NP, No JH, Luyen BT, Yang G, Byun SY, et al. (2014) Secondary metabolites from Vietnamese marine invertebrates with activity against trypanosoma brucei and T cruzi Molecules 19(6): 7869-7880.

3. Leal MC, Puga J, Serôdio J, Gomes NCM, Calado R (2012) Trends in the discovery of new marine natural products from invertebrates over the last two decades - where and what are we bioprospecting? PLoS One p. 7.

4. Sima P, Vetvicka V (2011) bioactive substances with anti-neoplastic efficacy from marine invertebrates: Porifera and Coelenterata. World J Clin Oncol 2(11): 355-361.

5. Blunt JW, Copp BR, Munro MHG, Northcote PT, Prinsep MR (2005) Marine natural products. Nat Prod Rep 30(2): 237-323.

6. Kim SK, Van Ta Q (2012) Bioactive Sterols from Marine Resources and Their Potential Benefits for Human Health. Adv Food Nutr Res 65: 261268.

7. Senthilkumar K, Kim SK (2013) Marine invertebrate natural products for anti-inflammatory and chronic diseases. Evidence-based Complement. Altern Med.

8. El-Shitany NA, Shaala LA, Abbas AT, Abdel-Dayem UA, Azhar EI, et al. (2015) Evaluation of the anti-inflammatory, antioxidant and immunomodulatory effects of the organic extract of the red sea marine sponge xestospongia testudinaria against carrageenan induced rat paw inflammation. PLoS One 10(9).

9. Wright AD, Nielson JL, Tapiolas DM, Motti CA, Ovenden SP, et al. (2009) Detailed NMR, including 1,1-ADEQUATE, and anticancer studies of compounds from the echinoderm Colobometra perspinosa. Mar Drugs 7(4): 565-575.

10. Madhu VN, P Sivaperumal, K Kamala, Ajit A Ambekar, BG Kulkarni, et al. (2014) Antibacterial and Antioxidant Activities of the Tissue Extract of Perna viridis Linnaeus, 1758 (Mollusca: Bivalvia) from Versova Coast, Mumbai. Int J Pharm Pharm Sci 6(S2): 704-707.

11. Sumitha R, Banu N, Deepa Parvathi V (2017) Novel Natural Products from Marine Sea Stars. Curr Trends Miomedical Eng Biosci 2(4): 1-5.

12. Thao NP, Nguyen Xuan Cuong, Bui Thi Thuy Luyen, Nguyen Van Thanh, Nguyen Xuan Nhiem, et al. (2013) Anti-inflammatory Asterosaponins from the. J Nat Prod 76(9): 1764-1770.

13. Malyarenko TV, Kicha AA, Ivanchina NV, Kalinovsky AI, Popov RS, et al. (2014) Asterosaponins from the Far Eastern starfish Leptasterias ochotensis and their anticancer activity. Steroids 87: 119-127.

14. Cheng G, Zhang X, Tang HF, Zhang Y,Zhang XH, et al. (2006) Asterosaponin 1 , a cytostatic compound from the starfish Culcita novaeguineae, functions by inducing apoptosis in human glioblastoma U87MG cells. J Neurooncol 79(3): 235-241.

15. Tang HF, Yi YH, Li L, Sun P, Zhang SQ, et al. (2006) Asterosaponins from the starfish Culcita novaeguineae and their bioactivities. Fitoterapia 77(1): 28-34.

16. Nam KS, Shon YH (2009) Chemo preventive effects of polysaccharides extract from Asterina pectinifera on HT-29 human colon adenocarcinoma cells. BMB Rep 42: 277-280.

17. Kicha AA, Ivanchina NV, Huong TT, Kalinovsky AI, Dmitrenok PS, et al. (2012) two new asterosaponins, archasterosides A and B, from the Vietnamese starfish Archaster typicus and their anticancer properties. Bioorg Med Chem Lett. 20(12): 3826-3830.

18. Wang W, Li F, Hong J, Lee CO, Cho HY, et al. (2003) Four New Saponins from the Starfish Certonardoa semiregularis. Chem Pharm Bull 51(4): 435-439.

19. Ferreres F, Pereira DM, Gil-Izquierdo A, Valentão P, Botelho J, et al. (2010) HPLC-PAD-atmospheric pressure chemical ionization-MS metabolite profiling of cytotoxic carotenoids from the echinoderm Marthasterias glacialis (spiny sea-star). J Sep Sci 33(15): 22500-2257. 
20. Suguna A, Bragadeeswaran S, Natarajan E, Mohanraj M (2014) Studies on antioxidant properties of starfish Luidia maculata. J Coast. Life Med 2: 694-698.

21. Zhanga W, Wanga J, Jing W, Zhanga Q (2013) The antioxidant activities and neuroprotective effect of polysaccharides from the starfish Asterias rollestoni. Carbohydr Polym 95(1): 9-15.

22. Llacuna ME J, Walag AMP, Villaluz EA (2016) Diversity and dispersion patterns of echinoderms in Babanlagan, Talisayan, Misamis Oriental, Philippines. Environ Exp Biol 14: 213-217.
23. Walag AMP, Canencia MOP (2016) Physico-chemical parameters and macrobenthic invertebrates of the intertidal zone of Gusa, Cagayan de Oro City, Philippines. AES Bioflux 8.

24. Achacoso S, Walag AM, Saab L (2016) A Rapid Assessment of Foliage Spider Fauna Diversity in Sinaloc, El Salvador City, Philippines: A Comparison between Habitats Receiving Different Degrees of Disturbance. Biodiversity 17: 156-161.

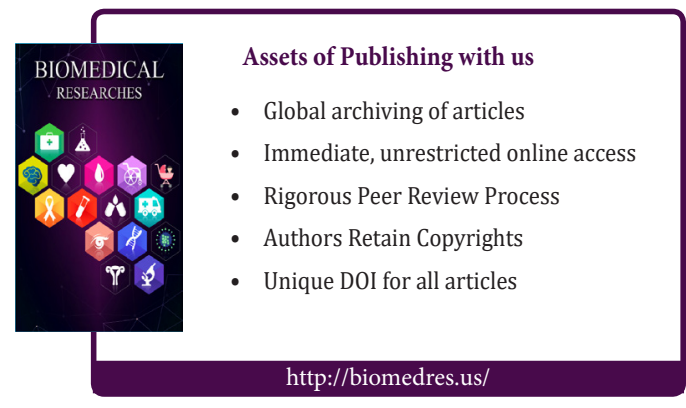

